\title{
Role of the vascular endothelium and plaque in acute ischemic stroke
}

Jane A. Madden, PhD

Correspondence $\&$ reprint requests to Dr. Madden: janeamadden@aol.com

\section{ABSTRACT}

The underlying cause of stroke lies in the damage to the arterial endothelial cell layer. The most profound damage is due to atherosclerosis, which can either occlude an artery or produce a thromboembolism. Diabetes and inflammation contribute to atherosclerosis and the associated endothelial damage by initiating and promoting the deposition of modified lipids in the subendothelium and by inhibiting endothelial nitric oxide (NO) production. At the same time, both production of endothelin-1 and generation of reactive oxygen species increase. In addition, leukocytes adhere to the endothelium and levels of $\mathrm{C}$-reactive protein increase. The stroke that ensues upon cerebral artery occlusion or plaque rupture continues and exacerbates endothelial damage. Statins have been shown to be helpful in preventing stroke and diminishing its consequences. An international clinical trial to determine if an NO donor is effective (Efficacy of Nitric Oxide in Stroke study) is currently under way. Other interventions such as antioxidants, $\rho$ kinase inhibition, and endothelial progenitor cells offer promising avenues of research and perhaps therapeutic avenues for treatment of stroke. This article discusses the role of the vascular endothelium in ischemic stroke and those interventions that may provide plausible avenues for future therapy. Neurology ${ }^{\circledR}$ 2012;79 (Suppl 1):S58-S62

\section{GLOSSARY}

BMSCs = bone marrow stromal cells; CRP = C-reactive protein; EDHF = endothelium-derived hyperpolarizing factor; eNOS = endothelial nitric oxide synthase; EPC = endothelial progenitor cell; ET = endothelin; HT = hemorrhagic transformation; MMPs = matrix metalloproteases; NO = nitric oxide; RAAS = renin-angiotensin-aldosterone system; ROS = reactive oxygen species.

Stroke is a heterogeneous phenomenon that arises from a multitude of disruptions, diseases, and insults to the arterial wall. The most serious consequence of these is atherosclerosis, which has become the leading cause of death in the developing world. ${ }^{1}$ Atherosclerosis contributes either directly to a stroke through occlusion of a cerebral artery or indirectly by the production of a distal thromboembolism. The list of risk factors for both atherosclerosis and stroke reads like a litany of modern society's ills: smoking, obesity, hypertension, diabetes, and inflammation arising from systemic diseases or recurrent infections. This article summarizes the roles of atherosclerosis and the vascular endothelium in cerebral ischemia.

ATHEROSCLEROSIS Atherosclerosis is a progressive deposition of modified lipids in the subendothelial layers. During the process, macrophages oxidize and phagocytose low-density lipoproteins to form lipid peroxides, thereby upregulating adhesion molecules. ${ }^{2}$ Cholesterol esters accumulate and foam cells form, processes which lead to further deterioration of endothelial cell function. Once the endothelium is physically or metabolically impaired, arterial smooth muscle cells proliferate, leading to further narrowing of the vessel lumen. Mast cells release metalloproteinases and elastase, both of which contribute to eventual plaque rupture and stroke (figure). ${ }^{3}$

ENDOTHELIUM The endothelium, the single layer of cells on the luminal surface of an artery, is a metabolically active interface between blood and tissue that modulates blood flow and nutrient delivery as well as regulating blood coagulation and thrombosis. ${ }^{4}$ The endothelium is also responsible for synthesis of the major vasodilators nitric oxide (NO), prostaglandins, and endothelium-derived hyperpolarizing factor (EDHF). It also

From the Department of Neurology, The Medical College of Wisconsin, Milwaukee; and Research Service, Zablocki Veterans Administration Medical Center, Milwaukee, WI.

Go to Neurology.org for full disclosures. Disclosures deemed relevant by the author, if any, are provided at the end of this article. 


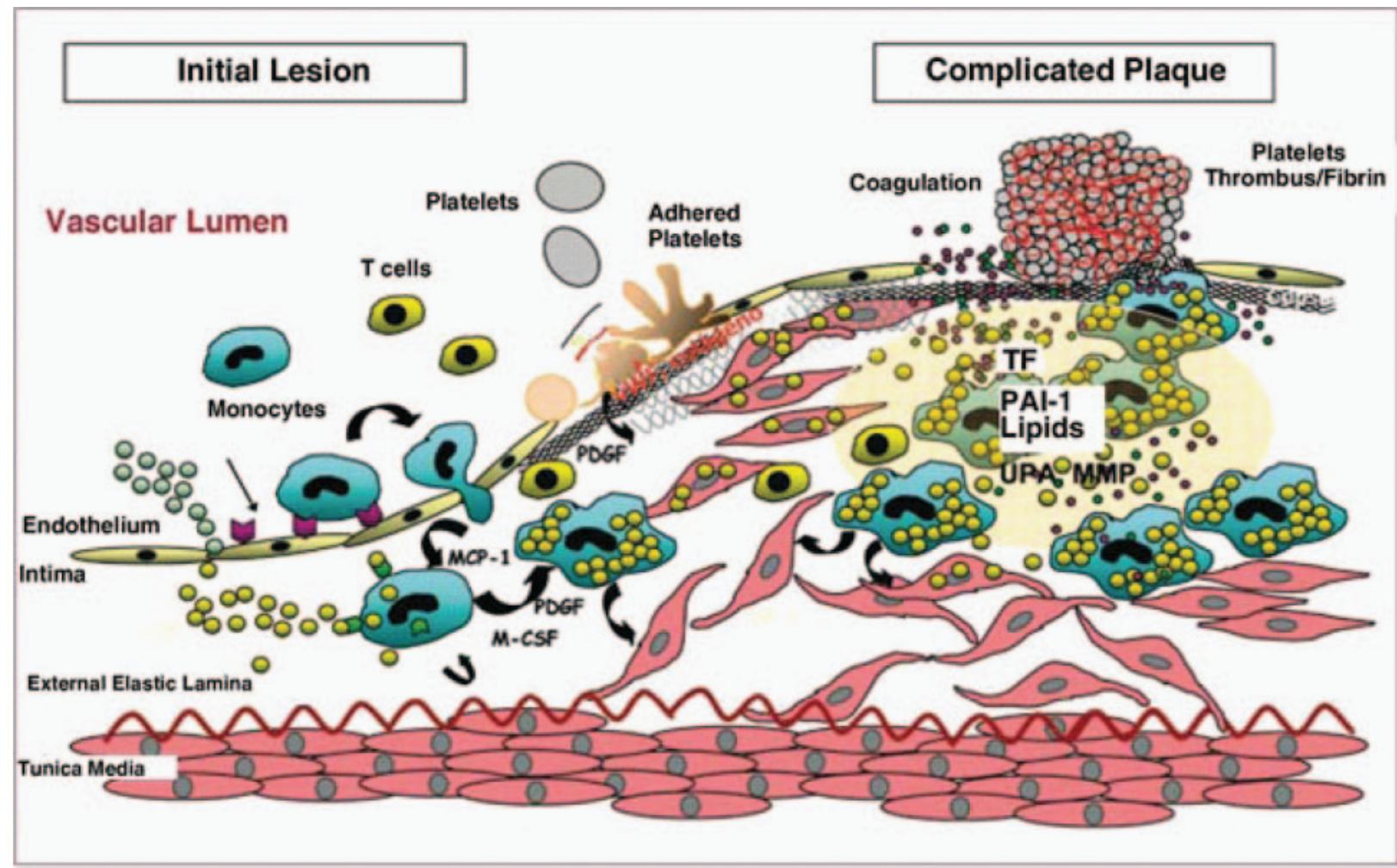

$\mathrm{M}-\mathrm{CSF}=$ macrophage colony-stimulating factor; $\mathrm{MCP}-1$ = monocyte chemotactic protein-1; MMP = metalloproteinases; PAI-1 = plasminogen activator inhibitor-1; PDGF = platelet-derived growth factor; TF = tissue factor; UPA = urokinase plasminogen activator. (Reprinted with permission from Badimon et al. ${ }^{3}$ )

synthesizes the powerful vasoconstrictors endothelin (ET) and angiotensin II. In addition, the endothelium is a rich source of reactive oxygen species (ROS), which are known for triggering as well as being produced by inflammation.

$\mathrm{NO}$, which is synthesized from L-arginine by the enzyme eNOS (endothelial NO synthase), is important not only for its vasodilator effects but also for its role in the inhibition of smooth muscle cell growth and proliferation, limiting of inflammation, and reduction of platelet aggregation. NO protects against ischemic stroke by increasing collateral flow to ischemic areas of the brain. ${ }^{5}$ Damage to the endothelium-whether gross denudation, disturbances in shear stresses, or the formation of atherosclerotic plaque-significantly impairs the dilatory and inhibitory functions.

FACTORS PREDISPOSING TO ATHEROSCLEROSIS AND STROKE Renin-angiotensin-aldosterone system. Activation of the renin-angiotensin-aldosterone system (RAAS) and the resultant elevations in angiotensin II and aldosterone contribute to altered insulin/ insulin-like growth factor-1 signaling pathways, insulin resistance, and ROS formation. This cascade impairs endothelium-mediated vasodilation and leads to angiotensin II-mediated vasoconstriction and hypertension, as well as pathologic growth and remodeling of the vasculature. ${ }^{6}$ One of the mechanisms that underlies aldosterone-dependent remodeling may involve the upregulation of a family of zinc-dependent proteases known as matrix metalloproteases (MMPs). ${ }^{7}$ MMPs are primary proteolytic enzymes that turn over the vascular extracellular matrix by attacking type IV collagen, laminin, and fibronectin, components of the basal lamina around cerebral blood vessels. ${ }^{8}$

Diabetes. Both prediabetes and diabetes impair NOmediated vasodilation, even before atheroma formation. ${ }^{4}$ Activation of eNOS is blocked, and there is increased endothelial cell production of ROS, especially superoxide. Superoxide further reduces the vasodilator effects of NO. A reaction between $\mathrm{NO}$ and the ROS yields peroxynitrite, which uncouples eNOS by oxidizing the NO synthesis cofactor tetrahydrobiopterin, resulting in the production of $\mathrm{O}_{2}$ by eNOS. ${ }^{9}$ This blunted eNOS expression and resulting reduction in $\mathrm{NO}$ production become a vicious cir$\mathrm{cle}^{10}$ : atherosclerotic lesions form or progress in size, platelets interact directly on intact endothelial cells, and the number of endothelial progenitor cells (EPCs) decreases, all resulting in an even greater deficiency of eNOS. An excess of free fatty acids, pro- 
duced as a consequence of diabetes, exacerbates endothelial damage. These fatty acids activate protein kinase $\mathrm{C}$, inhibit phosphatidylinositol-3 kinase (an eNOS agonist pathway), and increase ROS. The end result is that not only does NO production decrease, but what little NO is produced becomes less available. ${ }^{4}$ The formation of peroxynitrite by the reaction of $\mathrm{NO}$ and ROS also decreases the synthesis of the other prominent vasodilator, prostacyclin.

The increased activation of both endothelial and vascular cell nuclear factor $\kappa \beta$ and activator protein regulates the expression of genes that participate in atherogenic processes. Leukocyte-cell adhesion molecules form on the endothelium, and leukocyteattracting chemokines are produced. ${ }^{4}$ Ultimately, production of the potent vasoconstrictors ET-1 and angiotensin II, along with vasoconstrictor prostanoids, reduces the arterial lumen and leads to even greater complications in a lumen already constricted with arterial plaque.

Inflammation. Acute or chronic inflammation occurs throughout life. Every infection-respiratory, urinary tract, dental - either acute or chronic, can cause development or exacerbation of atherosclerosis. ${ }^{2}$ The steady and progressive damage due to inflammatory events accumulates over time, and when inflammation and infection interact with genetic predisposition and traditional risk factors, the risk of stroke may be enhanced. ${ }^{2}$ As mentioned earlier, there is a strong association between inflammation and vascular risk factors such as diabetes, smoking, hypertension, and hyperlipidemia, and the inflammatory indexes such as leukocyte count, C-reactive protein (CRP), and fibrinogen.

Inflammatory damage to the vasculature is mediated by complex mechanisms. ${ }^{2}$ Briefly, inflammatory cells such as macrophages and T-lymphocytes deposit in the subendothelial cell layer and cause release of inflammatory mediators or growth factors, including interleukins, tumor necrosis factor $\alpha$, interferons, transforming growth factor $\beta$, and CRP. In addition, monocyte chemotactic protein-1 and macrophage protein $1 \alpha$ are released from glial cells and bind to the endothelium. Intracellular adhesion molecule-1, E-selectin, tissue factor, and plasminogen activator inhibitor-1 are upregulated to facilitate leukocyte adherence. Thrombomoduline and tissue plasminogen activator are downregulated.

Elevated levels of CRP, a biomarker of inflammation, are correlated with cardiovascular disease risk and endothelial cell dysfunction, ${ }^{11}$ including blunted expression and function of eNOS and NO synthase $1,{ }^{12}$ and impaired re-endothelialization of the artery. ${ }^{13}$ Elevated CRP levels are closely associated with the inflammatory process, including the production of adhesion molecules, plasminogen activators, endothelin-1, and interleukin.

DAMAGE FOLLOWING STROKE When an atherosclerotic plaque ruptures, subendothelial proteins, including von Willebrand factor and collagen, are exposed. Platelets then adhere to these proteins and become activated by thromboxane $\mathrm{A}_{2}$ and secretion of platelet granules. Generation and release of soluble platelet agonists leads to platelet aggregation and the formation of an occluding thrombus. ${ }^{14,15}$ The cerebrovascular damage is early and progressive. ${ }^{9}$ Preexisting damage to the arterial wall due to atherosclerosis is compounded by cerebral edema and hemorrhagic transformation (HT) following the stroke. The significant increase in MMP levels after stroke may contribute to both the edema and HT. ${ }^{16}$

Disruption of the blood-brain barrier, often as a result of administration of tissue plasminogen activator, can also lead to edema and $\mathrm{HT}^{17}$ and contribute to an additional increase in ET-1 production and decreased angiopoietin. The actin cytoskeleton of the vessel is altered and myogenic tone is impaired, leading to loss of autoregulation in the cerebral circulation. Even more damaging is the massive production of ROS, particularly superoxide. Superoxide contributes to altered responses to acetylcholine and $\mathrm{CO}_{2}$, increased platelet aggregability, further disruption of the endothelial layer, and increased blood-brain barrier permeability. There is more disruption of the endothelial cells, as well as increased peroxynitrite production. Unlike superoxide, peroxynitrite is not a free radical but a powerful oxidant that triggers inflammation and apoptosis. All of this damage is exacerbated in patients with diabetes and may be correlated with the reduced number of circulating EPCs. ${ }^{18}$

Recently, a study using MRI suggested that type VI atherosclerotic plaque (cap rupture, hemorrhage, or thrombosis) in unstable patients with symptoms of TIA or stroke could help relate plaque characteristics to the acute clinical event. Further work is needed to determine whether plaque characterization by MRI will proved to be useful in the detection of presymptomatic lesions at risk of rupture. ${ }^{19}$

Can endothelial function be improved pre- or poststroke? Considerable research efforts have been directed toward improving and repairing endothelial function both pre- and poststroke.

Statins. The most promising therapy certainly seems to be the statins. Statins augment NO production and produce anti-inflammatory and antithrombotic factors, along with immunomodulation to limit endothelial damage. ${ }^{20}$ Abrupt withdrawal of statins can lead to the overshoot activation of Rho 
GTPase and nicotinamide adenine dinucleotide phosphate (NADPH) oxidase complex (Rac-1), a negative regulation of eNOS expression, and decrease of NO bioavailability. Other consequences include an oxidative burst and $\mathrm{NO}$ scavenging by superoxide, inflammation, and thrombosis. ${ }^{20}$

The Efficacy of Nitric Oxide in Stroke clinical trial. The Efficacy of Nitric Oxide in Stroke (ENOS) study has been undertaken to determine the safety and efficacy of 1) transdermal glyceryl trinitrate (an NO donor) or a control and 2) continuing or temporarily stopping prior antihypertensive medication in patients with ischemic or hemorrhagic stroke. This clinical study is a collaborative, international, multicenter, prospective, randomized, single-blind, blinded-endpoint, parallel-group, controlled trial that since its beginning in 2003 has (as of mid-2011) enrolled over 2,300 patients worldwide.

Antioxidants and other compounds. Antioxidants administered pre- or poststroke are also another source of investigation, although most studies have been done in animals. Ginkgo biloba, superoxide dismutase, and aspirin have been investigated, with varying degrees of success. ${ }^{?}$

ET receptor antagonists, particularly for the $\mathrm{ET}_{\mathrm{A}}$ receptor, may turn out to be useful, because blockage with S-0139 suppresses blood-brain barrier disruption and brain edema. ${ }^{21}$ Whether inhibiting $\mathrm{ET}_{\mathrm{B}}$ receptors will be similarly useful is not yet certain, since the response may result in different results under control and disease (diabetic) conditions. ${ }^{16}$

Ivrabradine, an inhibitor of the $\mathrm{I} 9(f)$ current in the sinoatrial node that lowers heart rate without affecting blood pressure or contractility, was effective in reducing infarct volume in mice with occluded cerebral arteries, presumably due to improved endothelium function and reduced oxidative stress. ${ }^{22}$ Doxycycline has been found to inhibit MMPs, ${ }^{7}$ and hyperbaric oxygen treatment appears to decrease inflammation as well as reduce the upregulation of MMPs and inhibit hemorrhagic transformation after stroke. $^{23}$

$\boldsymbol{\rho}$ Kinase inbibition. Selective $\rho$ kinase inhibitors have been shown to increase eNOS expression and NO production and have anti-inflammatory actions. ${ }^{5}$ They appear to decrease the size of the cerebral infarct, improve the neurologic deficit score, and increase cerebral blood flow through collateral circulation.

Endothelial progenitor cells and bone marrow stromal cells. Endothelial progenitor cells are an exciting new area of investigation. These immature endothelial cell-derived bone marrow stem cells circulate in peripheral blood. ${ }^{24,25}$ Endothelial injury appears to act as a trigger for these cells in the repair of damaged endothelial cells. Such a potential "miracle cure" has both benefits and risks. On the positive side, in ani- mal studies, EPCs have been shown to participate in the formation of new vessels and to increase blood flow in ischemic areas. ${ }^{25}$ Increased levels of circulating EPCs and reduced ischemic damage were found after diabetic mice with middle cerebral artery occlusion were infused with EPCs preincubated with wildtype membrane microparticles. ${ }^{18}$

EPC numbers can be increased by exercise and with ACE inhibitors and receptor blockers, statins, and erythropoietin. ${ }^{24}$ No studies have been done in cerebral vessels, and there are concerns that enhanced revascularization of cerebral vessels may lead to edema. Another concern is that the similarity of EPCs to hematopoietic progenitor cells raises the possibility that these cells could differentiate into monocytes and macrophages and thereby aggravate ischemia, through an increase in inflammation. ${ }^{24}$ In addition to EPCs, the endothelium expresses selectins that produce a proadhesive phenotype, which favors attachment of bone marrow stromal cells (BMSCs) and leads to recruitment of regenerative stem cells to the ischemic area. ${ }^{26}$

DISCUSSION Stroke has a number of risk factors, many of which can be controlled by adherence to a healthy lifestyle. However, when the arterial endothelium is injured due to one or a combination of these risk factors, the damage is insidious, progressive, and multifactorial. Identification of therapeutic targets for existing drugs such as statins and NO, along with the development of future treatments such as $\rho$ kinase inhibition, EPCs, and BMSCs, may offer hope of prevention and cure for stroke.

\section{AUTHOR CONTRIBUTIONS}

Dr. Madden: drafting/revising the manuscript for content.

\section{DISCLOSURE}

Dr. Madden received an honorarium for presenting the talk at the Society for Vascular Interventional Neurology (SVIN) meeting, attending the SVIN roundtable, and writing the manuscript; served on the Editorial Board of Respiratory Research; and has received research support from the National Science Foundation. Go to Neurology.org for full disclosures.

Received June 27, 2011. Accepted in final form September 7, 2011.

\section{REFERENCES}

1. Malek AM, Alper SL, Izumo S. Hemodynamic shear stress and its role in atherosclerosis. JAMA 1999;282:20352042.

2. Lindsberg PJ, Grau AJ. Inflammation and infections as risk factors for ischemic stroke. Stroke 2003;34:25182532.

3. Badimon L, Vilahur G, Padro T. Lipoproteins, platelets and atherothrombosis. Rev Esp Cardiol 2009;62:11611178.

4. Beckman JA, Creager MA, Libby P. Diabetes and atherosclerosis: epidemiology, pathophysiology, and management. JAMA 2002;287:2570-2581. 
5. Rikitake $\mathrm{Y}$, Kim $\mathrm{H}-\mathrm{H}$, Huang Z, et al. Inhibition of Rho kinase (ROCK) leads to increased cerebral blood flow and stroke protection. Stroke 2005;36:2251-2257.

6. Cooper SA, Whaley-Connell A, Habibi J, et al. Reninangiotensin-aldosterone system and oxidative stress in cardiovascular insulin resistance. Am J Physiol Heart Circ Physiol 2007;293:H2009-H2023.

7. Pires PW, Rogers CT, McClain JL, Garver HS, Fink GD, Dorrance AM. Doxycycline, a matrix metalloprotease inhibitor, reduces vascular remodeling and damage after cerebral ischemia in stroke-prone spontaneously hypertensive rats. Am J Physiol Heart Circ Physiol 2011;301:H87-H97.

8. Montaner J, Alvarez-Sabin J, Molina CA, et al. Matrix metalloproteinase expression is related to hemorrhagic transformation after cardioembolic stroke. Stroke 2001; 32:2762-2767.

9. Fagan SC, Hess DC, Hohnadel EJ, Pollock DM, Ergul A. Targets for vascular protection after acute ischemic stroke. Stroke 2004;35:2220-2225.

10. Massberg S, Schurzinger K, Lorenz M, et al. Platelet adhesion via glycoprotein IIb integrin is critical for atheroprogression and focal cerebral ischemia: an in vivo study in mice lacking glycoprotein IIb. Circulation 2005;112: $1180-1188$.

11. Mineo C, Gormley AK, Yuhanna IS, et al. Fc $\gamma$ RIIB mediates C-reactive protein inhibition of endothelial NO synthase. Circ Res 2005;97:1124-1131.

12. Wang Q, Zhu X, Xu Q, Ding X, Chen YE, Song Q. Effect of $\mathrm{C}$-reactive protein on gene expression in vascular endothelial cells. Am J Physiol Heart Circ Physiol 2005;288: H1539-H1545.

13. Schwartz R, Osborne-Lawrence S, Hahner L, et al. $\mathrm{C}$-reactive protein downregulates endothelial NO synthase and attenuates reendothelialization in vivo in mice. Circ Res 2007;100:1452-1459.

14. Reininger AJ, Bernlochner I, Penz SM, et al. A 2-step mechanism of arterial thrombus formation induced by human atherosclerotic plaques. J Am Coll Cardiol 2010;55: $1147-1158$.

15. Choi J, Kermode JC. New therapeutic approaches to combat arterial thrombosis: better drugs for old targets, novel targets, and future prospects. Mol Interv 2011;11:111-123.

16. Kelly-Cobbs AI, Harris AK, Elgebaly MM, et al. Endothelial endothelin B receptor-mediated prevention of cerebro- vascular remodeling is attenuated in diabetes because of up-regulation of smooth muscle endothelin receptors. J Pharmacol Exp Ther 2011;337:9-15.

17. Moldes O, Sobrino T, Millan M, et al. High serum levels of endothelin-1 predict severe cerebral edema in patients with acute ischemic stroke treated with t-PA. Stroke 2008; 39:2006-2010.

18. Chen J, Chen S, Chen Y, et al. Circulating endothelial progenitor cells and cellular membrane microparticles in $\mathrm{db} / \mathrm{db}$ diabetic mouse: possible implications in cerebral ischemic damage. Am J Physiol Endocrinol Metab 2011; 301:E62-E71.

19. Parmar JP, Rogers WJ, Mugler JP 3rd, et al. Magnetic resonance imaging of carotid atherosclerotic plaque in clinically suspected acute transient ischemic attack and acute ischemic stroke. Circulation 2010;122:20312038.

20. Endres M, Laufs U. Discontinuation of statin treatment in stroke patients. Stroke 2006;37:2640-2643.

21. Zhang RL, Zhang C, Zhang L, et al. Synergistic effect of an endothelin type A receptor antagonist, S-0139, with rtPA on the neuroprotection after embolic stroke. Stroke 2008;39:2830-2836.

22. Custodis F, Gertz K, Balkaya M, et al. Heart rate contributes to the vascular effects of chronic mental stress: effects on endothelial function and ischemic brain injury in mice. Stroke 2011;42:1742-1749.

23. Qin Z, Karabiyikoglu M, Hua Y, et al. Hyperbaric oxygeninduced attenuation of hemorrhagic transformation after experimental focal transient cerebral ischemia. Stroke 2007;38:1362-1367.

24. Rouhl RPW, van Oostenbrugge RJ, Damoiseaux J, Cohen Tervaert J-W, Lodder J. Endothelial progenitor cell research in stroke: a potential shift in pathophysiological and therapeutical concepts. Stroke 2008;39:2158-2165.

25. Chu K, Jung K-H, Lee S-T, et al. Circulating endothelial progenitor cells as a new marker of endothelial dysfunction or repair in acute stroke supplemental methods. Stroke 2008;39:1441-1447.

26. Yilmaz G, Vital S, Yilmaz CE, Stokes KY, Alexander JS, Granger DN. Selectin-mediated recruitment of bone marrow stromal cells in the postischemic cerebral microvasculature. Stroke 2011;42:806-811. 


\section{Neurology}

\section{Role of the vascular endothelium and plaque in acute ischemic stroke \\ Jane A. Madden \\ Neurology 2012;79;S58-S62 \\ DOI 10.1212/WNL.0b013e3182695836}

This information is current as of September 24, 2012

\section{Updated Information \&}

Services

References

Subspecialty Collections

Permissions \& Licensing

Reprints including high resolution figures, can be found at:

http://n.neurology.org/content/79/13_Supplement_1/S58.full

This article cites 26 articles, 17 of which you can access for free at: http://n.neurology.org/content/79/13_Supplement_1/S58.full\#ref-list-1

This article, along with others on similar topics, appears in the following collection(s):

All Cerebrovascular disease/Stroke

http://n.neurology.org/cgi/collection/all_cerebrovascular_disease_strok e

Information about reproducing this article in parts (figures,tables) or in its entirety can be found online at:

http://www.neurology.org/about/about_the_journal\#permissions

Information about ordering reprints can be found online:

http://n.neurology.org/subscribers/advertise

Neurology ${ }^{\circledR}$ is the official journal of the American Academy of Neurology. Published continuously since 1951, it is now a weekly with 48 issues per year. Copyright Copyright (? 2012 by AAN Enterprises, Inc.. All rights reserved. Print ISSN: 0028-3878. Online ISSN: 1526-632X.

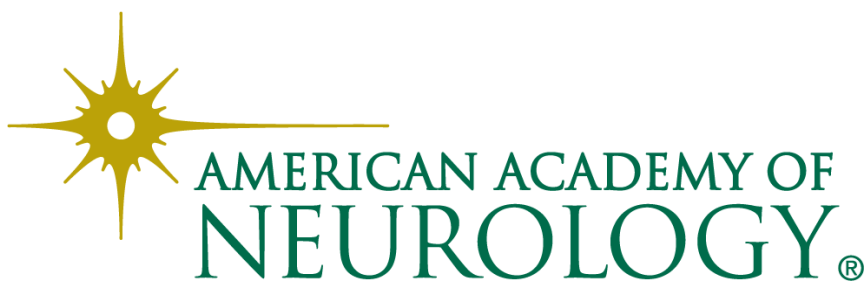

